\title{
STATISTICAL ASPECTS OF SOME FATIGUE CRACK GROWTH DATA
}

\author{
W. F. $\mathrm{Wu}^{1}$ and C. C. $\mathrm{Ni}^{2}$ \\ ${ }^{1}$ Department of Mechanical Engineering, National Taiwan University, Taipei, 10617 Taiwan \\ ${ }^{2}$ Department of Mechanical Engineering, China Institute of Technology, Taipei, 10716, Taiwan
}

\begin{abstract}
To study the reliability of aging aircraft structures, fatigue crack growth tests have been carried out for a considerable amount of specimens made of 2024 T-351 aluminum alloy. Their results are reported in the present paper with special emphasis on the scatter and statistical aspect of these fatigue crack growth data. In total, there are three data sets obtained, two of them are tested under constant-amplitude loading and the other under random loading. Statistical analysis is performed for these data sets and the results are compared with those of other available data sets. In consideration of the random loading cycle to reach a specific crack size and the random crack size at a specific loading cycle, it is found that the standard deviation of each quantity increases as fatigue crack grows for all three data sets obtained in the present study. Similar trends are also observed in data sets published previously by others. The coefficient of variation of loading cycle decreases while the coefficient of variation of crack size increases as fatigue crack grows for all three data sets presented in this study. It is, however, not the case for data sets published by others. Moreover, it is concluded that the inhomogenity of material does cause the scatter of fatigue crack growth. Whether the randomness of the applied load increases or decreases the scatter, however, needs to be investigated further since there is no unique result for all data sets compared. Cumulative distributions of random loading cycle to reach specific crack sizes obtained by solving probabilistic models of fatigue crack growth curves are also presented, and conclusions are drawn. Other comments on statistical and stochastic analyses of fatigue crack growth are made as well.
\end{abstract}

\section{INTRODUCTION}

It is known that fatigue crack growth of engineering materials exhibits a wide range of scatter, even under the same loading condition in a strictly controlled environment with specimens cut from the same sheet. To take into account the scatter, it is important to analyze fatigue crack growth data from a statistical viewpoint. In fact, many researchers have carried out studies in this aspect [1-9], and many stochastic fatigue crack growth models have been proposed to depict the scattering of the crack growth process [10-18]. To proceed with the investigation, experimental data are always needed. However, it is rather time-consuming to carry out experiments to obtain sets of statistically meaningful fatigue crack growth data. Until now, there are only a few data sets available in the literature. Among them, the most famous and frequently used data set perhaps is the one obtained by Virkler et al. [1]. Two more frequently mentioned data sets include one reported by Ghonem and Dore [19] and the other released by the Flight Dynamics Laboratory of the US Air Force [20]. As a result, many stochastic fatigue crack growth models are either lack of experimental verification or verified by only one data set. It is felt that more experimental data sets are needed for researchers to verify the applicability of their models. Therefore, in the present paper, three newly obtained and statistically meaningful fatigue crack growth data sets are presented, two of them under constant-amplitude loading test and the other under random loading test. Statistical analyses are performed on these data and their results are compared with those obtained from other published data sets. These newly obtained data are also used to verify several stochastic fatigue crack growth models proposed by either the writers or other researchers. 
Comments on results of the analyses are made at the end of the paper.

\section{FATIGUE CRACK GROWTH EXPERIMENT}

The experimental setup for obtaining the fatigue crack growth data consists of an MTS dynamic testing machine, a machine controller, a LabView signal generating/data acquisition system and a crack length measurement system. Compact tension (CT) specimens cut from a 2024-T351 aluminum-alloy plate were used for the fatigue crack growth tests. The dimensions of the specimens are $50.0 \mathrm{~mm}$ wide (counting from the loading line to the back face of the specimens) and $12.0 \mathrm{~mm}$ thick. For constant-amplitude loading fatigue experiment, two sets of specimen subjected to different loading conditions were tested. The first set, named CA1 (constantamplitude loading set 1 ) hereafter for simplicity, consists of 30 specimens. They were tested under a sinusoidal load of $p_{\text {peak }}=4.5 \mathrm{kN}$ and $p_{\text {trough }}=0.9 \mathrm{kN}$. The second set consists of 10 specimens and is named CA2 hereafter. They were tested under the sinusoidal load of $p_{\text {peak }}=6.118 \mathrm{kN}$ and $p_{\text {trough }}=3.882 \mathrm{kN}$. For the random loading fatigue experiment, a set of 25 specimens named VA1 (variable-amplitude loading set 1) were tested under sequential random loads generated in accordance with the spectral theory. When transformed to terms used by fatigue experimentalists, the random load has $p_{\text {peak }}=6.118 \mathrm{kN}, p_{\text {trough }}=3.882 \mathrm{kN}$, and $p_{\text {amplitude }}=1.118 \mathrm{kN}$, all in the sense of mean value. The experimental fatigue crack growth curves of CA1 and VA1 are shown in Figure 1(a) and 1(b), respectively. A considerable degree of scatter can be seen from these figures.

\section{STATISTICAL OBSERVATION}

Based on the above experimental results and applying descriptive statistics, the mean values, standard deviations and coefficients of variation (COV) of several random quantities shown in Figure 1 were obtained. In particular, statistics of the random loading cycles for the crack size to reach specific values are shown in Table 1 and plotted in Figure 2. Statistics for the crack sizes at specific loading cycles are also shown in Figure 2. It is interesting to note that the standard deviation of the loading cycles (to reach specific crack sizes) increases as the crack grows. The same trend is found for the standard deviation of crack sizes (at specific loading cycles). However, the COV of loading cycle decreases smoothly, while the COV of crack size increases rapidly as the crack grows.

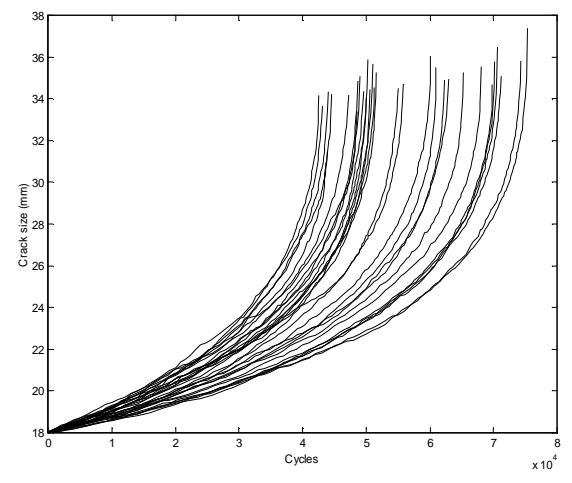

(a)

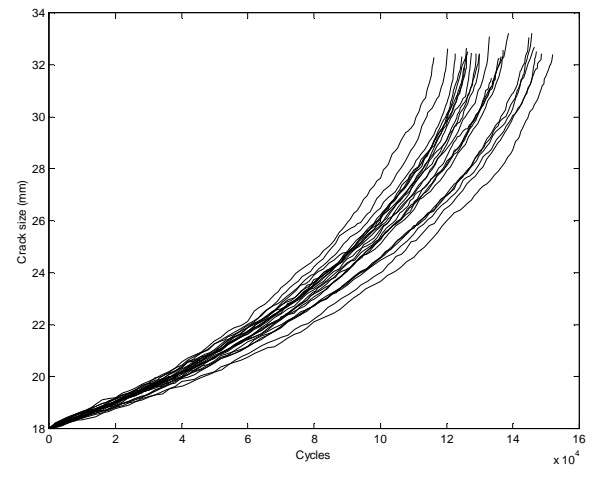

(b)

Figure 1: Crack growth curves tested under (a) constant amplitude loading, (b) random loading. 
Table 1: Statistics of loading cycles to reach specified crack lengths

\begin{tabular}{rrrrrrrr}
\hline Data set & \multicolumn{7}{c}{ Crack size $(\mathrm{mm})$} \\
\hline \multirow{3}{*}{ CA1 } & \multicolumn{1}{c}{20} & \multicolumn{1}{c}{22} & \multicolumn{1}{c}{24} & \multicolumn{1}{c}{26} & \multicolumn{1}{c}{28} & \multicolumn{1}{c}{30} \\
& $\mu$ & 19,441 & 32,792 & 41,917 & 48,042 & 51,984 & 54,356 \\
& $\sigma$ & 4,129 & 6,198 & 7,863 & 8,832 & 9,503 & 9,860 \\
& $\mathrm{COV}$ & 0.212 & 0.189 & 0.188 & 0.184 & 0.183 & 0.181 \\
\hline \multirow{3}{*}{$\mathrm{CA} 2$} & $\mu$ & 72,082 & 128,221 & 166,138 & 194,794 & 215,083 & 230,645 \\
& $\sigma$ & 9,473 & 15,170 & 17,130 & 19,163 & 20,792 & 21,143 \\
& $\mathrm{COV}$ & 0.131 & 0.118 & 0.103 & 0.098 & 0.097 & 0.092 \\
\hline \multirow{2}{*}{$\mathrm{VA} 1$} & $\mu$ & 38,255 & 66,186 & 87,573 & 104,562 & 117,702 & 127,296 \\
& $\sigma$ & 3,290 & 5,139 & 6,710 & 7,204 & 8,410 & 8,822 \\
& $\mathrm{COV}$ & 0.086 & 0.078 & 0.077 & 0.069 & 0.071 & 0.069 \\
\hline
\end{tabular}
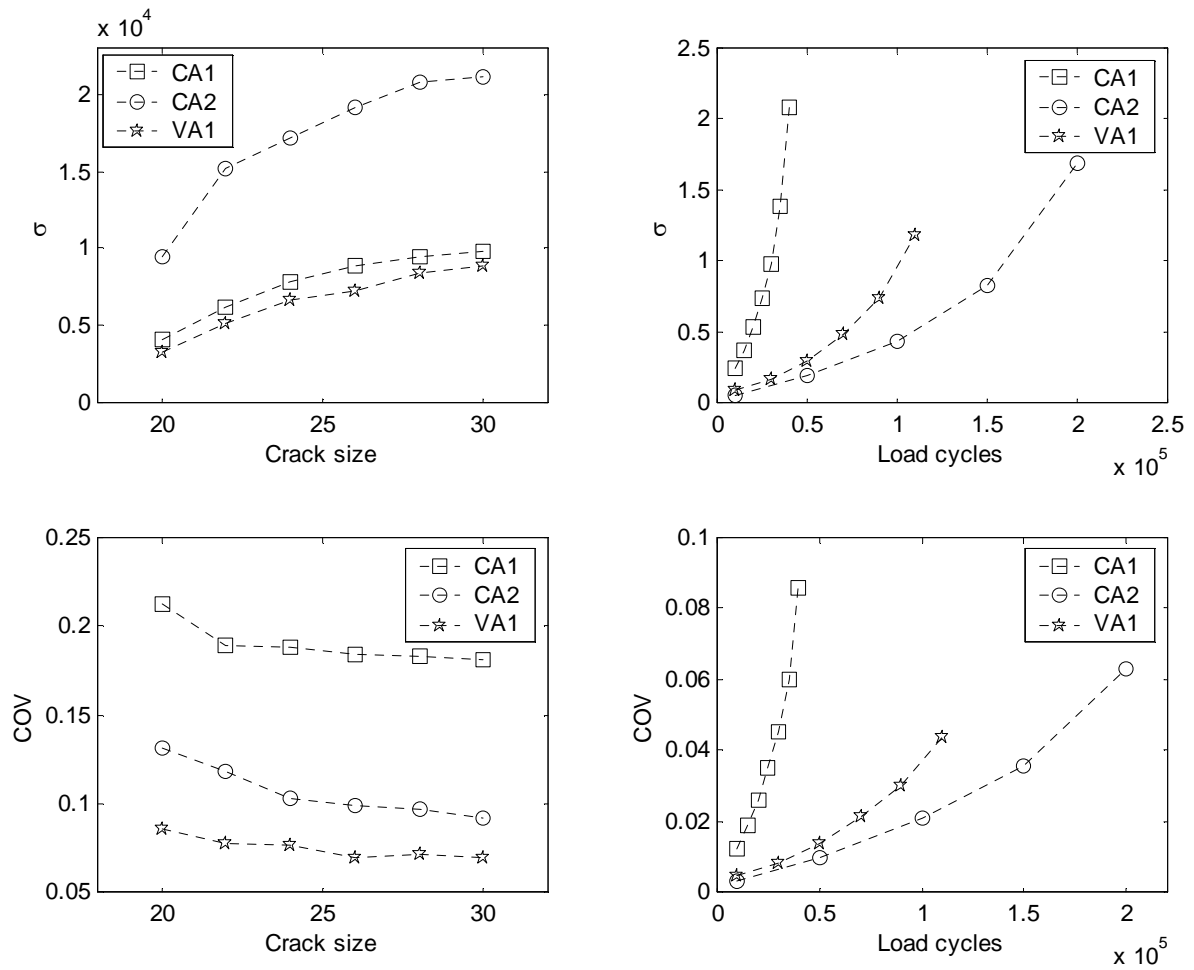

Figure 2: Variation of statistics.

To compare the above results with those obtained by other researchers, Table 2 was constructed in which CA3 indicates the data set published by Virkler et al. [1], and CA4 and VA2 are data sets published by Dominguez et al. [4]. All these data sets are statistically meaningful and all specimens are made of 2024-T3 series of aluminum alloy. Although the geometry, dimension, loading condition, and initial/final crack length recorded may be different, it is still of interest to 
Table 2: Comparison of scatter

\begin{tabular}{|c|c|c|c|c|c|c|c|}
\hline \multicolumn{2}{|c|}{ Data set } & $\begin{array}{c}\text { CA1 } \\
\text { (Present) }\end{array}$ & $\begin{array}{c}\text { CA2 } \\
\text { (Present) }\end{array}$ & CA3 [1] & CA4 [4] & $\begin{array}{c}\text { VA1 } \\
\text { (Present) }\end{array}$ & VA2 [4] \\
\hline \multicolumn{2}{|c|}{ Material } & 2024-T351 & 2024-T351 & 2024-T3 & 2024-T351 & 2024-T351 & 2024-T351 \\
\hline \multicolumn{2}{|c|}{ Specimen } & $\mathrm{CT}$ & $\mathrm{CT}$ & $\begin{array}{c}\text { Center cracked } \\
\text { panel }\end{array}$ & $\mathrm{CT}$ & CT & CT \\
\hline \multicolumn{2}{|c|}{ \# Tested } & 30 & 10 & 68 & 18 & 25 & 30 \\
\hline \multicolumn{2}{|c|}{ Loading } & $\begin{array}{l}P_{\text {max }}=4.5 \mathrm{kN} \\
P_{\text {min }}=0.9 \mathrm{kN}\end{array}$ & $\begin{array}{l}P_{\max }=6.1 \mathrm{kN} \\
P_{\min }=3.9 \mathrm{kN}\end{array}$ & $\begin{array}{l}P_{\text {max }}=18.68 \mathrm{kN} \\
P_{\text {min }}=4.67 \mathrm{kN}\end{array}$ & $\begin{array}{l}P_{\max }=4.5 \mathrm{kN} \\
P_{\min }=0.9 \mathrm{kN}\end{array}$ & $\begin{array}{c}5.00 \mathrm{kN} \\
\pm \text { random } \\
\text { (diff. hist.) }\end{array}$ & $\begin{array}{c}4.83 \mathrm{kN} \\
\pm \text { random } \\
\text { (diff. hist.) }\end{array}$ \\
\hline \multirow[b]{2}{*}{$a_{0}$} & $\mu$ & \multirow[t]{2}{*}{$18.00 \mathrm{~mm}$} & \multirow[t]{2}{*}{$18.00 \mathrm{~mm}$} & \multirow[t]{2}{*}{$9.00 \mathrm{~mm}$} & \multirow[t]{2}{*}{$17.5 \mathrm{~mm}$} & \multirow[t]{2}{*}{$18.00 \mathrm{~mm}$} & $15.03 \mathrm{~mm}$ \\
\hline & $\frac{\sigma}{\mathrm{COV}}$ & & & & & & $\begin{array}{l}0.052 \mathrm{~mm} \\
0.0034\end{array}$ \\
\hline \multicolumn{2}{|c|}{$a_{f}$} & Fracture & $32.00 \mathrm{~mm}$ & $49.80 \mathrm{~mm}$ & $27.8 \mathrm{~mm}$ & $32.00 \mathrm{~mm}$ & $25.3 \mathrm{~mm}$ \\
\hline \multicolumn{2}{|c|}{$\begin{array}{c}a \\
\text { considered } \\
\text { below }\end{array}$} & $30.00 \mathrm{~mm}$ & $30.00 \mathrm{~mm}$ & $36.20 \mathrm{~mm}$ & $27.8 \mathrm{~mm}$ & $30.00 \mathrm{~mm}$ & $25.3 \mathrm{~mm}$ \\
\hline \multirow{3}{*}{$N$} & $\mu$ & 54,356 & 230,645 & 234,573 & 56,985 & 127,296 & 159,777 \\
\hline & $\sigma$ & 9,860 & 21,144 & 10,191 & 2,288 & 8,822 & 15,272 \\
\hline & $\mathrm{COV}$ & 0.181 & 0.0917 & 0.043 & 0.040 & 0.0693 & 0.096 \\
\hline
\end{tabular}

make comparison among these data sets. According to Dominguez et al. [4], the scatter of fatigue crack growth may be attributed to material inhomogeneity or random loading. Through examining COVs of loading cycle of data sets CA1, CA2, CA3 and CA4 in Table 2, it is concluded that the inhomogeneity of material does cause the scatter of fatigue crack growth, and the degree of scatter may be considerably large. By comparing the COV values of CA4 and VA2, Dominguez et al. [4] pointed out that random loading produces additional scatter. On the contrary, the present data sets CA1, CA2, and VA1 show a reduction of scatter from constant amplitude loading to random loading. Therefore, the effect of random loading on the scatter of fatigue crack growth remains unknown and needs to be studied more carefully.

Since there are more crack growth curves as samples, the data sets of CA1 and VA1 have been used for the verification of several stochastic fatigue crack growth models [17-18]. It was found that Bogdanoff and Kozin's Markov chain model [10], Yang's randomized Paris-Erdogan model [14] and a polynomial model proposed by the writers [18] can all describe data set CA1 very well, and the Markov chain and polynomial models can depict data set VA1 most accurately. The cumulative distributions of loading cycle to reach a few specific crack sizes for data set VA1 by the polynomial model are shown in Figure 3. After a detailed study, it is concluded that each of the above models may be the most appropriate one to depict some particular sets of data but not necessarily the others.

\section{CONCLUDING REMARKS}

Three newly obtained fatigue crack growth data sets of 2024-T351 aluminum-alloy specimens are presented in the present paper. Statistical analysis of the experimental data is performed and the 

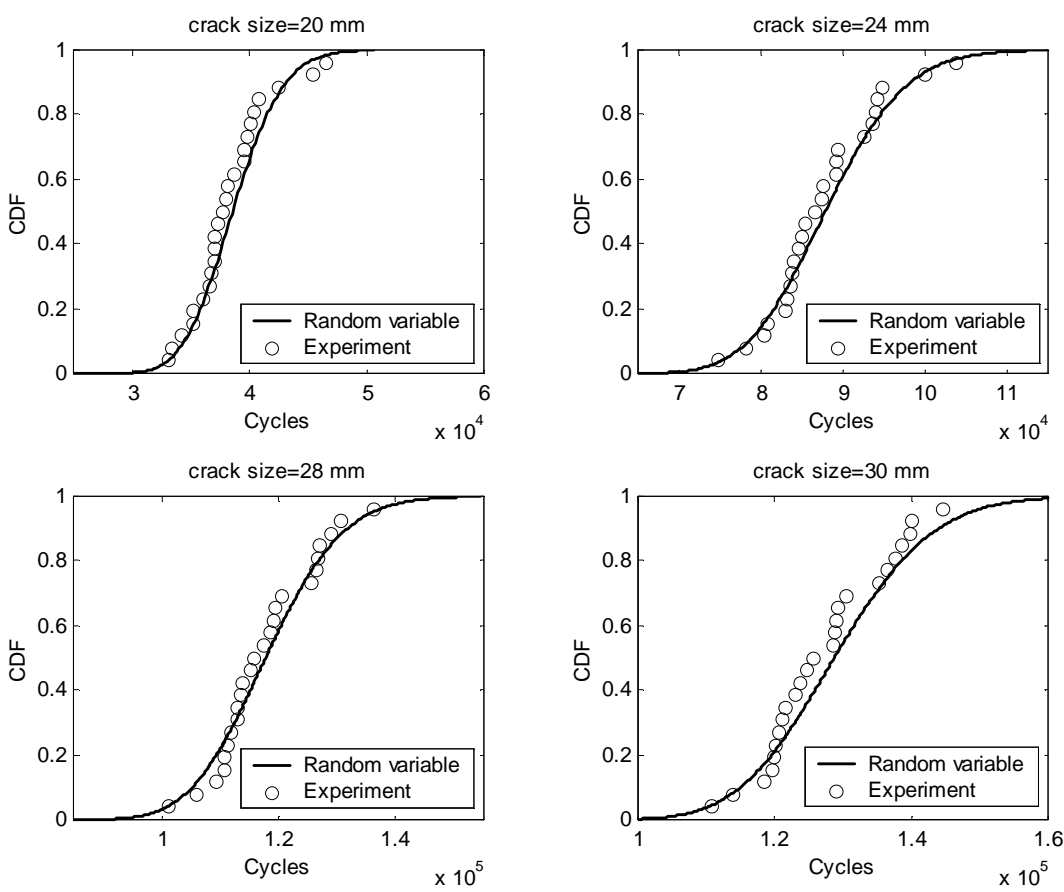

Figure 3: Cumulative distributions of loading cycle.

results are compared with those obtained from other published data sets. The newly obtained data are also used for the verification of several probabilistic fatigue crack growth models. It is hoped that the experimental fatigue crack growth data released and analyzed in this and its associated papers would provide researchers sources and references to further investigate the scatter of fatigue crack growth, and to verify or modify their stochastic or probabilistic crack growth models.

With regard to the statistical nature of the fatigue crack growth, the following phenomena are observed and comments are made at the end of the paper.

1. The standard deviation of both loading cycle and crack size increases as fatigue crack grows for all three data sets presented in this study. Similar trends are also observed in other data sets.

2. The coefficient of variation of loading cycle decreases while the coefficient of variation of crack size increases as fatigue crack grows for all three data sets obtained by us. It is, however, not the case for other data sets published previously.

3. The inhomogeneity of material does cause the scatter of fatigue crack growth, and the degree of scatter may be considerably large. It, of course, also deviates from one to another manufacturer.

4. In addition to the material inhomogeneity, whether random load increase or decrease the scatter of the fatigue crack growth remains unknown and needs to be studied more carefully.

5. The randomized Paris-Erdogan and polynomial stochastic fatigue crack growth models are considered more accurate and appropriate to describe the fatigue crack growth data presented in this paper. 


\section{ACKNOWLEDGEMENTS}

This work is supported by the National Science Council of the Republic of China under Grant No. NSC 91-2212-E-002-070. The writers are grateful for this support.

\section{REFERENCES}

[1] Virkler DA, Hillberry BM, Goel PK. The statistic nature of fatigue crack propagation. ASME Journal of Engineering Materials and Technology, 101: 148-153, 1979.

[2] Schijve J. Fatigue predictions and scatter. Fatigue \& Fracture of Engineering Materials \& Structures, 17(4): 381-396, 1994.

[3] Dominguez J, Zapatero, J. Effect of the loading spectrum and history length on fatigue life distribution under random loading. Engineering Fracture Mechanics, 42(6): 925-933, 1992.

[4] Dominguez J, Zapatero J, Pascual J. Effect of the load histories on scatter of fatigue crack growth in aluminum alloy 2024-T351. Engineering Fracture Mechanics, 56(1): 65-76, 1997.

[5] Itagaki H, Ishizuka T, Huang PY. Experimental estimation of the probability distribution of fatigue crack growth lives. Probabilistic Engineering Mechanics, 8(1): 25-34, 1993.

[6] Alawi H. Fatigue crack growth prediction under random peaks and sequence loading. ASME Journal of Engineering Materials and Technology, 111: 338-343, 1989.

[7] Bergner F, Zouhar G. A new approach to the correlation between the coefficient and the exponent in the power law equation of fatigue crack growth. International Journal of Fatigue, 22: 229-239, 2000.

[8] Wu WF, Shin CS, Shen JJ. Probabilistic analysis of fatigue crack propagation under random loading. ASME Journal of Pressure Vessel Technology, 116: 216-225, 1994.

[9] Liou HY, Ni CC, Wu WF. Scatter and statistical analysis of fatigue crack growth data. Journal of the Chinese Society of Mechanical Engineers, 22(5): 399-407, 2001.

[10] Bogdanoff JL, Kozin F. A new cumulative damage model, part 4. ASME Journal of Applied Mechanics, 47(1): 40-44, 1980.

[11] Lin YK, Yang JN. A stochastic theory of fatigue crack propagation. AIAA Journal, 23: 117-124, 1985.

[12] Tanaka H, Tsurui A. Reliability degradation of structural components in the process of fatigue crack propagation under stationary random loading. Engineering Fracture Mechanics, 27(5): 501-516, 1987.

[13] Sobczyk K, Spencer BF. Random Fatigue: From Data to Theory. Academic Press, 1992.

[14] Yang JN, Manning SD. A simple second order approximation for stochastic crack growth analysis. Engineering Fracture Mechanics, 53(5): 677-686, 1996.

[15] Rocha MM, Schueller GI, Okamura H. The fitting of one- and two-dimensional fatigue crack growth laws. Engineering Fracture Mechanics, 44: 473-480, 1993.

[16] Rocha MM, Schueller GI. A probabilistic criterion for evaluating the goodness of fatigue crack growth models. Engineering Fracture Mechanics, 53: 701-731, 1996.

[17] Wu WF, Ni CC. A study of stochastic fatigue crack growth modeling through experiment data. Probabilistic Engineering Mechanics, 18: 107-118, 2003.

[18] Wu WF, Ni CC. Probabilistic models of fatigue crack propagation and their experimental verification. Accepted and to appear in Probabilistic Engineering Mechanics 2004.

[19] Ghonem H, Dore S. Experimental study of the constant probability crack growth curves under constant amplitude loading. Engineering Fracture Mechanics, 27: 1-25, 1987.

[20] Yang JN, Hsi WH, Manning SD. Stochastic crack propagation with applications to durability and damage tolerance analyses. Technical Report, Flight Dynamics Laboratory, US Wright-Patterson Air Force Base, AFWAL-TR-85-3062, 1985. 